\title{
Tidally induced velocity variations of the Beardmore Glacier, Antarctica, and their representation in satellite measurements of ice velocity
}

\author{
O. J. Marsh ${ }^{1}$, W. Rack ${ }^{1}$, D. Floricioiu ${ }^{2}$, N. R. Golledge ${ }^{3,4}$, and W. Lawson ${ }^{5}$ \\ ${ }^{1}$ Gateway Antarctica, University of Canterbury, Private Bag 4800, Christchurch, New Zealand \\ ${ }^{2}$ German Aerospace Centre (DLR), Oberpfaffenhofen, 82234 Weßling, Germany \\ ${ }^{3}$ Antarctic Research Centre, Victoria University of Wellington, P.O. Box 600, Wellington, New Zealand \\ ${ }^{4}$ GNS Science, Avalon, Lower Hutt 5011, New Zealand \\ ${ }^{5}$ Department of Geography, University of Canterbury, Private Bag 4800, Christchurch, New Zealand
}

Correspondence to: O. J. Marsh (oliver.marsh@pg.canterbury.ac.nz)

Received: 8 April 2013 - Published in The Cryosphere Discuss.: 29 April 2013

Revised: 17 July 2013 - Accepted: 23 July 2013 - Published: 10 September 2013

\begin{abstract}
Ocean tides close to the grounding line of outlet glaciers around Antarctica have been shown to directly influence ice velocity, both linearly and non-linearly. These fluctuations can be significant and have the potential to affect satellite measurements of ice discharge, which assume displacement between satellite passes to be consistent and representative of annual means. Satellite observations of horizontal velocity variation in the grounding zone are also contaminated by vertical tidal effects, the importance of which is highlighted here in speckle tracking measurements. Eight TerraSAR-X scenes from the grounding zone of the Beardmore Glacier are analysed in conjunction with GPS measurements to determine short-term and decadal trends in ice velocity. Diurnal tides produce horizontal velocity fluctuations of $>50 \%$ on the ice shelf, recorded in the GPS data $4 \mathrm{~km}$ downstream of the grounding line. This variability decreases rapidly to $<5 \%$ only $15 \mathrm{~km}$ upstream of the grounding line. Daily fluctuations are smoothed to $<1 \%$ in the 11 day repeat pass TerraSAR-X imagery, but fortnightly variations over this period are still visible and show that satellitevelocity measurements can be affected by tides over longer periods. The measured tidal displacement observed in radar look direction over floating ice also allows the grounding line to be identified, using differential speckle tracking where
\end{abstract}

phase information cannot be easily unwrapped.

\section{Introduction}

The Antarctic Ice Sheet contains approximately $27000000 \mathrm{Gt}\left(10^{12} \mathrm{~kg}\right)$ of ice (Fretwell et al., 2013). Recent estimates suggest around $2000 \mathrm{Gt}$, or $0.01 \%$, of this ice moves through the system every year (Rignot et al., 2008), which is a volume equivalent to around $5 \mathrm{~mm}$ per year of global sea level rise. It is clear that even a small imbalance between inputs and outputs could cause a rapid change in global sea level. Accurate methods of identifying ice discharge around the perimeter of Antarctica are necessary to quantify the mass balance of individual glaciers and allow modelling of current and future contribution of the ice sheets to sea level rise. Discharge of outlet glaciers is typically calculated at the grounding line where ice becomes floating and before it moves into a regime of net negative mass balance on the ice shelf influenced by significantly enhanced basal melting (Rignot and Jacobs, 2002).

Frequent measurement of surface displacement allows observation of dynamic changes in glacier velocity. The velocity of ice streams and outlet glaciers terminating in ice shelves has been shown to fluctuate in response to ocean 
tides (e.g. Anandakrishnan et al., 2003; Bindschadler et al., 2003; Gudmundsson, 2006), and when analysing long-term trends it is important not to include bias from these shortterm, unrepresentative velocity variations, or misuse a velocity 'snapshot' taken over a few days to calculate an annual average ice discharge (Doake et al., 2002; Joughin et al., 2005; Gudmundsson, 2006). The frequency and amplitude of the tidally induced response varies with location, with velocity increases between 100 and $300 \%$ of the mean recorded near the calving margins of large ice shelves (Brunt et al., 2010; Makinson et al., 2012) and smaller variations recorded tens of kilometres upstream of the grounding line on fast-flowing ice streams (Gudmundsson, 2006). Variations close to the grounding line have been linked to perturbation in basal shear stress (Bindschadler et al., 2003; Anandakrishnan et al., 2003), but it is not yet clear how longitudinal stresses are transmitted within the ice shelf (Brunt et al., 2010). Velocity also varies differently depending on the strength of tidal components, with a non-linear response of velocity associated with the semi-diurnal tides (King et al., 2010) and more regular response to diurnal tides (Bindschadler et al., 2003).

A full understanding of the drivers of this velocity fluctuation is of particular importance when annual velocity patterns are calculated using interferometric synthetic aperture radar (InSAR) or other satellite measurements of surface displacement calculated over short intervals (Gudmundsson, 2006). In the last two decades InSAR has become a standard way of measuring ice sheet surface velocities remotely (Goldstein et al., 1993; Rignot, 1996; Rignot et al., 2008). This technique relies on the satellite acquisitions being separated by a short time interval in order that snowfall events or other changes in the surface do not reduce the interferometric coherence. For spaceborne InSAR, repeat pass acquisitions are typically separated by several days to weeks depending on the repeat cycle of the satellite. Here we use velocity data from GPSs at points upstream and downstream of the grounding line to quantify the temporal variability in velocity in the grounding zone, both on daily timescales and over the last $50 \mathrm{yr}$. Using these data in combination with a tide model (Padman et al., 2008) and glacier response model (Gudmundsson, 2007), we extend the measured GPS time series and predict how these variations will be visible from satellite speckle tracking. Synthesized velocities are compared with real satellite acquisitions and used to make inferences about the spatial extent of short-term velocity changes observed at GPS points and their propagation upstream of the grounding line.

TerraSAR-X and ground-based velocity measurements are presented for Beardmore Glacier, an outlet glacier in the Transantarctic Mountains, Antarctica. The high accuracy of TerraSAR-X speckle tracking also allows a method of grounding line identification using techniques similar to differential interferometry (Goldstein et al., 1993; Rignot et al., 2011) but possible where phase coherence is not necessarily continuous or fringes are too densely spaced to be unwrapped (Joughin et al., 2010).

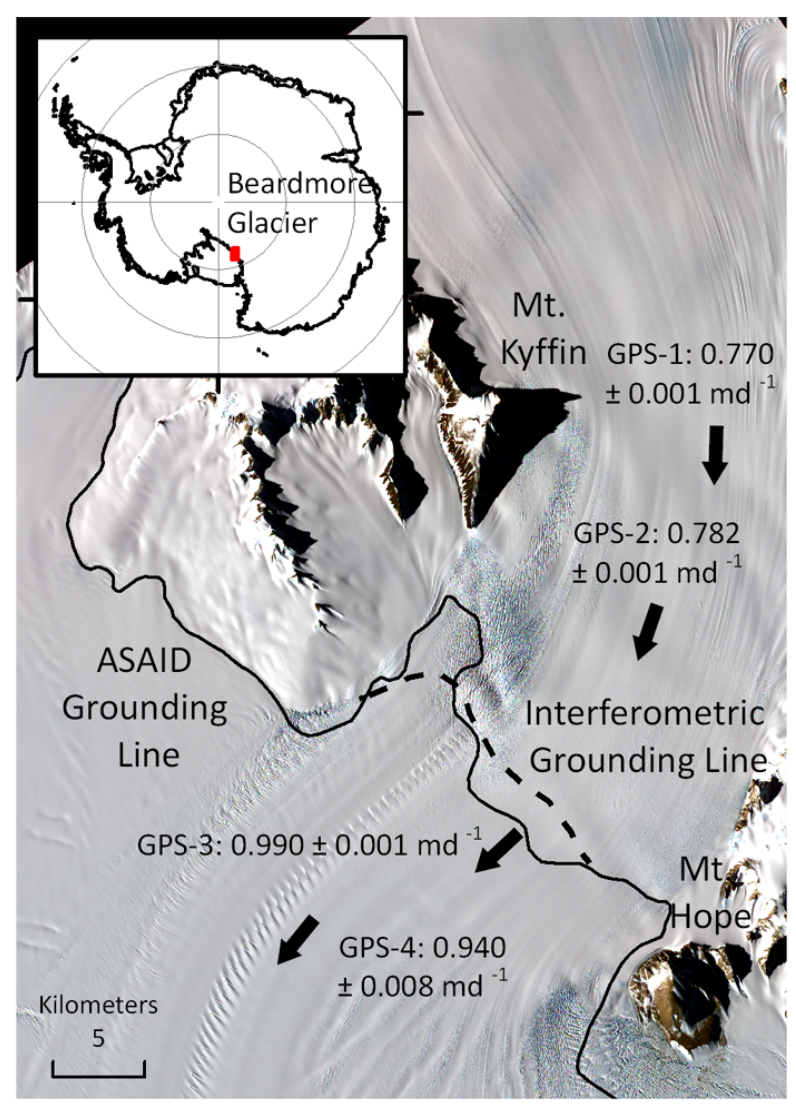

Fig. 1. Beardmore Glacier GPS positions and velocities in December 2010 superimposed on an ASTER image from 2008. GPS positions correspond to the centres of arrows. The ASAID (solid line) and interferometric (dashed line) grounding lines are also shown.

\section{The Beardmore Glacier}

The glaciers which flow through the Transantarctic Mountains provide an important link between the West Antarctic and East Antarctic Ice Sheets, and understanding their flow and variability is important for monitoring how mass balance changes can be transmitted across the ice sheet. The Beardmore Glacier $\left(83.5^{\circ} \mathrm{S}, 172^{\circ} \mathrm{E}\right)$ drains a catchment of around $90000 \mathrm{~km}^{2}$ from East Antarctica into the Ross Ice Shelf (Fig. 1). The glacier flows steeply through the Transantarctic Mountains with a well-defined break of slope where it meets the ice shelf, between Mount Hope and Mount Kyffin, and is around $25 \mathrm{~km}$ wide at this point. Previous measurements of the Beardmore Glacier are limited due to its high latitude and inaccessibility. A velocity of $364.7 \pm 1.5 \mathrm{ma}^{-1}$ $\left(0.998 \pm 0.004 \mathrm{md}^{-1}\right)$ was calculated for the Beardmore in $1960-1961$ by measuring stakes over a period of close to $1 \mathrm{yr}$ on the central flowline of the glacier close to the grounding line (Swithinbank, 1963) with a coincident measurement over 14 days during the summer agreeing with these results to within $2 \%$ (the limit of detection), and suggesting limited seasonal variability at this time. 
The grounding line of the Beardmore is defined here using two methods: photoclinometrically to identify a surface impression of change in stress regime, and interferometrically identifying the landward limit of tidal flexure (Fig. 1). A photoclinometric grounding line is available from the Antarctic Surface Accumulation and Ice Discharge (ASAID) full Antarctic grounding line map (Bindschadler et al., 2011), but no published landward limit of tidal flexure is available for this area. This was instead derived manually from a combination of TerraSAR-X differential interferograms (2012) and ICESat data (2003-2009) for the area. The two grounding lines differ by less than $2 \mathrm{~km}$, and where ICESat tracks cross the grounding line, data from Brunt et al. (2010) using flexure information and Marsh et al. (2012) using break of slope and surface deformation distribution also agree well with these grounding lines.

\section{GPS measurements}

GPS measurements are used to provide high temporal resolution information on glacier velocity. Four GPS stations (14) were positioned on the centreline of the glacier at $20 \mathrm{~km}$ and $10 \mathrm{~km}$ upstream and $4 \mathrm{~km}$ and $15 \mathrm{~km}$ downstream of the grounding line. GPS-3 was positioned on the coordinates of the 1960-1961 measurement in the grounding zone by Swithinbank (1963). Data at all sites were recorded at $15 \mathrm{sec}-$ ond intervals over a 35 -day period, although data are not continuous at some of the sites. These data have been processed using kinematic precise point positioning algorithms in JPL's GIPSY software (Zumberge et al., 1997; King, 2004). Effects of ionospheric and tropospheric delay are reduced by kinematic processing under loose random-walk constraints although some precision is lost in comparison to static occupation methods (e.g. King et al., 2000). Locational accuracy from this method is nominally between 1.5 and $2.5 \mathrm{~cm}$. Care was taken in resolving ambiguities in horizontal and vertical velocities to avoid errors in horizontal measurements due to unmodelled vertical signals (King, 2004). Point velocities are calculated based on differencing the positions over time intervals of 6 hours. This smoothes out high-frequency noise associated with the coordinate location errors and any unmodelled higher harmonic tides. A comparison between GPS measured velocity and vertical movement at GPS-3 is given in Fig. 2a. Local maxima in velocity in the grounding zone coincide with maximum rate of falling tide, which is in agreement with elastic flexure theory which predicts a longitudinal extension at the surface during low tide (Holdsworth, 1969). At GPS-3, $6 \mathrm{~h}$ mean velocities vary between $0.5 \mathrm{md}^{-1}$ and $1.5 \mathrm{md}^{-1}$ during spring tides.

\section{TerraSAR-X speckle tracking}

TerraSAR-X data are used to provide information on spatial variability of glacier velocity. Speckle tracking makes use of the high pixel noise inherent in coherent imaging systems such as SAR. Speckle tracking can be used to map displacement vectors over short periods, but unlike optical feature tracking it does not require large-scale features such as crevasses. This method can be applied where surface displacement is relatively large and phase coherence is not completely lost. Current and recent InSAR and speckle tracking calculations have used consecutive repeat pass acquisitions of the available spaceborne SAR missions with various repeat cycles, e.g. 1-day repeats, for instance with ERS-1/-2 in tandem mode (e.g. Joughin et al., 1996; Burgess et al., 2005); 3-day repeats such as with ERS-1 repeat pass acquisitions during the ice phase (e.g. Kwok and Fahnestock, 1996); 11-day repeats such as with TerraSAR-X (Jezek et al., 2011); 24-day repeats as with the Radarsat-1 (Scheuchl et al., 2012); and 46-day repeats with ALOS PALSAR (Baessler et al., 2012).

For the Beardmore Glacier grounding zone, eight TerraSAR-X scenes with 11-day separation have been acquired in StripMap mode: two sets of triples in March and June 2012 and an image pair in December 2009 (Table 1). Calculating displacement between these images allows five temporally distinct measurements of velocity. At $83.5^{\circ} \mathrm{S}$ the data are acquired in left-looking mode on a descending orbit and processed to single-look slant-range complex (SSC) format by DLR (Breit et al., 2010). A scene centre incidence angle of $44^{\circ}$ gives range pixel resolution of $2.5 \mathrm{~m}$ and azimuth resolution of $3.3 \mathrm{~m}$ for these scenes. TerraSAR-X scenes over the Beardmore are acquired with the radar look direction aligned approximately perpendicular to the main component of ice flow. Velocities are calculated from full-resolution SSC data by speckle amplitude tracking simultaneously in range and azimuth direction, which largely avoids coherence problems in fast-flowing areas and shear zones but provides subpixel resolution (Joughin, 2002). Co-registration of image pairs is done by masking out moving areas on the glacier and ice shelf, and calculating a base offset between images for the remaining areas. The slave image is then shifted to match this offset and produce a zero velocity over non-moving areas. Patches between 64 and 512 pixels square were tested for cross-correlation and a $256^{2}$ patch used for final matching, producing a high signal-to-noise ratio but minimum loss of spatial resolution. Correlations with poor signal-to-noise ratio are discarded. An oversampling factor is applied to increase the precision of correlation. Jezek et al. (2011) estimate an absolute error for TerraSAR imagery of $0.03 \mathrm{md}^{-1}$ from atmospheric path delay and solid earth tide effects. Relative velocity errors depend on patch size and shape of the correlation function but are here minimized due to large patch sizes. 


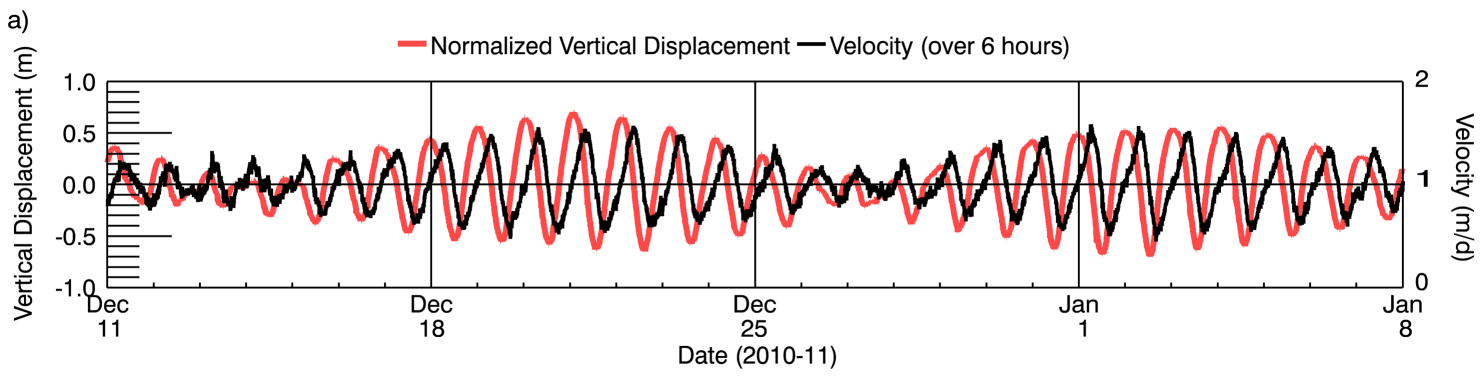

b)

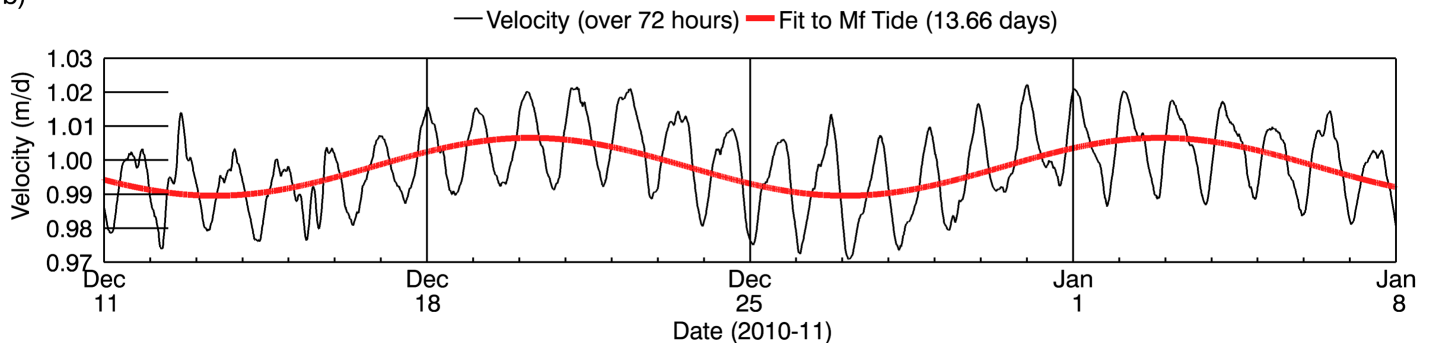

Fig. 2. (a) Recorded vertical displacement and $6 \mathrm{~h}$ averaged surface velocity at GPS-3. Peaks in velocity match closely to peak rate of falling tide both in phase and amplitude. (b) 3-day running average velocity at the Beardmore grounding line from GPS data. Velocities show the outcome of 3-day repeat feature tracking. Short-term velocities throughout the paper are given in $\mathrm{md}^{-1}$ instead of ma $^{-1}$.

Table 1. Modelled tidal height above mean sea level and inverse barometer effect derived from atmospheric pressure at "Elaine" weather station for individual TerraSAR-X acquisition dates.

\begin{tabular}{llrrr}
\hline TSX ID & Date & $\begin{array}{r}\text { Tide }(\mathrm{m}) \\
\text { (CATS_2008opt) }\end{array}$ & $\begin{array}{r}\text { Atmospheric } \\
\text { pressure (hPa) }\end{array}$ & $\begin{array}{r}\text { Inverse barometer } \\
\text { effect (m) }\end{array}$ \\
\hline Dec-1 & $16 / 12 / 09$ & 0.606 & $982.5^{*}$ & -0.175 \\
Dec-2 & $27 / 12 / 09$ & 0.024 & $981.7^{*}$ & -0.183 \\
Mar-1 & $20 / 03 / 12$ & 0.271 & 982.0 & -0.180 \\
Mar-2 & $31 / 03 / 12$ & -0.198 & 990.3 & -0.097 \\
Mar-3 & $11 / 04 / 12$ & -0.684 & 981.2 & -0.188 \\
Jun-1 & $05 / 06 / 12$ & -0.596 & 972.3 & -0.277 \\
Jun-2 & $16 / 06 / 12$ & -0.116 & 985.2 & -0.142 \\
Jun-3 & $27 / 06 / 12$ & -0.019 & 998.2 & -0.018 \\
\hline
\end{tabular}

* data from "Lettau" station $\left(83.1^{\circ} \mathrm{S}, 174^{\circ} \mathrm{E}\right)$

\section{Ice velocity results}

Averaged GPS data from December 2010 show a $1 \%$ decrease in velocity at the grounding line of the Beardmore Glacier over the $50 \mathrm{yr}$ period since 1960-1961 from $0.998 \pm 0.004 \mathrm{md}^{-1}$ to $0.990 \pm 0.001 \mathrm{md}^{-1}$. This difference is greater than the combined error estimates given for the 1960-1961 and 2010-2011 data but suggests that discharge from this glacier has remained stable over the last fifty years (Swithinbank, 1963) in contrast to glaciers elsewhere in Antarctica. A stacked velocity map using data from three pairs of TerraSAR-X data gives a smoothed spatial velocity over three 11-day periods (Fig. 3). Comparison between TerraSAR-derived velocities and GPS velocities highlights the absolute error in the TerraSAR-X data. TerraSAR-X and GPS velocities, respectively, in $\mathrm{md}^{-1}$ at GPS- 1 are 0.756 and
0.770 ; at GPS-2 are 0.748 and 0.782 ; at GPS-3 are 0.972 and 0.990; and at GPS-4 are 0.934 and 0.940 . This shows agreement within $5 \%$ at all sites and $<2 \%$ at all but one site, supporting estimates of TerraSAR-X error of around $0.03 \mathrm{md}^{-1}$.

\section{Grounding line identification}

Although the effect of tides becomes progressively less important with longer repeat pass intervals and speckle tracking has previously been used to infer a horizontal velocity independent of tidal interference (e.g. Baessler et al., 2012), with high-resolution sensors such as TerraSAR-X the quality of speckle tracking velocity measurements is high enough that vertical tidal effects are clearly observed in radar range and when not removed can introduce a large bias in 


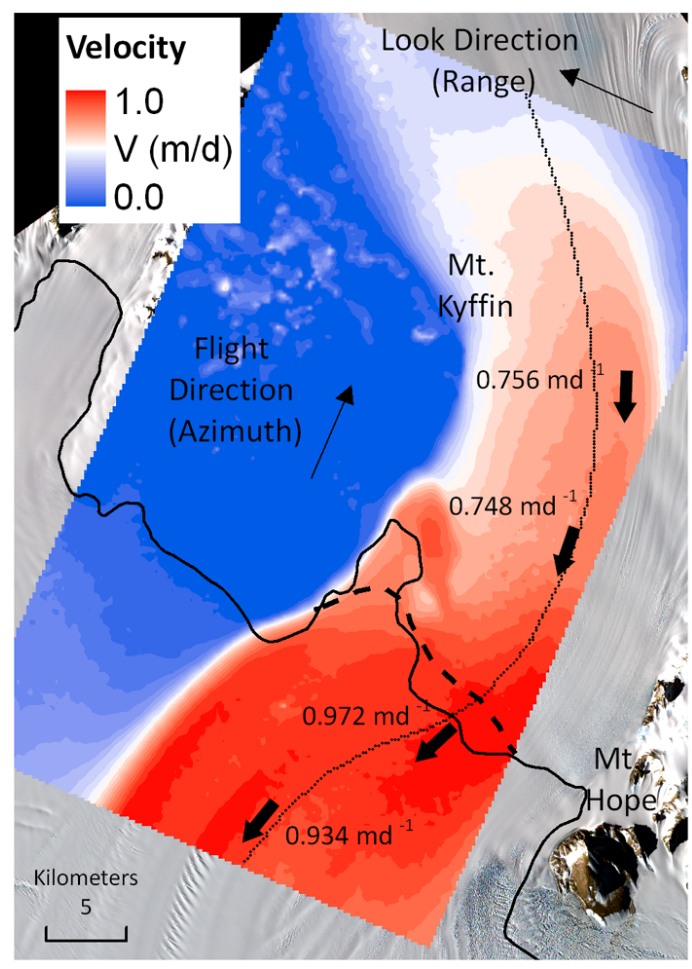

Fig. 3. Absolute velocity across the Beardmore Glacier grounding line created by stacking velocity data from $1 / 2$ December, $1 / 2$ June and 2/3 June. Velocity arrows show TerraSAR-X velocities at GPS points for comparison with Fig. 1.

horizontal velocity. At an incidence angle of $44^{\circ}$, a $1 \mathrm{~m}$ change in tide between satellite passes produces a $1.036 \mathrm{~m}$ error in the horizontal displacement, which translates to approximately $0.094 \mathrm{md}^{-1}$ error in velocity in look direction over the 11-day repeat pass interval of TerraSAR-X (Fig. 4). This is significant for many outlet glaciers and ice streams surrounding Antarctica, particularly where the main component of flow is in look direction, and must be removed in the velocity calculations. Where the main component of flow direction is in azimuth direction, there will instead be an net effect on estimated flow direction. Where the incidence angle is smaller than $44^{\circ}$, as is the case with many sidelooking radar systems, these biases will be further amplified. A $10 \%$ error as predicted by the vertical tidal movement between scenes should therefore be observable well above random noise in the TerraSAR-X data and can be used to map the grounding line.

The unmodified velocity difference map shown in Fig. 6a shows an apparent significant increase in velocity in radar look direction over the ice shelf between December 2009 and June 2012 with little change on the grounded ice. This increase averages around $0.09 \mathrm{md}^{-1}$, a difference that can be explained by error in calculated horizontal velocity induced by the vertical tidal movement of the ice shelf (Fig. 4). The 1-2 December tidal and atmospheric difference is $-0.589 \mathrm{~m}$

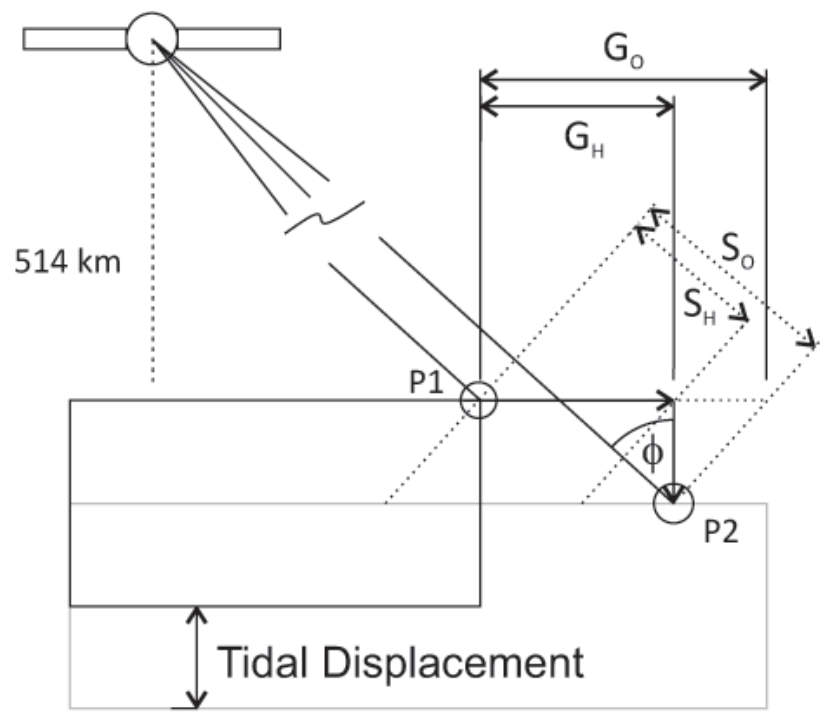

Fig. 4. Schematic showing the effect of tidal displacement on observed displacement in slant range $\left(S_{\mathrm{O}}\right)$ and ground range $\left(G_{\mathrm{O}}\right)$ compared to actual horizontal displacement $\left(G_{\mathrm{H}}\right)$. When slant range is converted into ground range the additional displacement equals the tidal change divided by the tangent of the incidence angle $(S=T / \tan (\phi))$.

and 1-2 June is $+0.615 \mathrm{~m}$, giving a double difference of $+1.204 \mathrm{~m}$ and expected velocity error of $0.113 \mathrm{md}^{-1}$ based on the radar incidence angle. This differential vertical movement allows identification of the areas of floating ice affected by the tides, similar to established techniques using interferometry (Goldstein et al., 1993; Rignot et al., 2011) but without the need for the high coherence in the often crevassed shear zones around the grounding line and continuously resolvable fringes required for phase unwrapping by InSAR.

\section{Tidally induced velocity change}

The Ross Ice Shelf has a relatively strong diurnal tide, particularly in the $\mathrm{K} 1(23.93 \mathrm{~h})$ and $\mathrm{O} 1(25.82 \mathrm{~h})$ components with modelled amplitudes of $0.5 \mathrm{~m}$ and $0.4 \mathrm{~m}$, respectively, at the Beardmore Glacier grounding line; conversely the semidiurnal tidal components are weak and close to zero, and the vertical movement of the ice shelf is consistently diurnal (Padman et al., 2008). A baseline for expected tidal range on the ice shelf was obtained from the CATS2008a_opt tide model (Padman et al., 2008) using eight major tidal components (K1, O1, P1, Q1, M2, S2, N2, K2). The response of ice shelves to changes in atmospheric pressure, known as the inverse barometer effect, adds a further centimetre of change per hecto-Pascal (Padman et al., 2003). These air pressure effects are accounted for using Antarctic weather station observations made at the "Elaine" weather station at $83.1^{\circ} \mathrm{S}, 174^{\circ} \mathrm{E}$ and at "Lettau" at $82.4^{\circ} \mathrm{S}, 174^{\circ} \mathrm{W}$ (Table 1 ). 
Temporal variation in load tide and solid earth tide is negligible and therefore neglected.

An equation linking tidally varying basal shear stress to forward surface movement was put forward by Gudmundsson $(2006,2007)$ and is shown to be robust in replicating observed velocity variations on the Rutford Ice Stream using vertical movement from a tide model where errors in the tide prediction are reasonable (King et al., 2010). This relationship is here used to extrapolate the observed GPS-3 coverage from 2010-2011 to the satellite data acquisition period from 2009-2012. GPS-3 is close to the grounding line and we assume the variability in ice flow at this point to be representative of the grounding zone. The forward velocity, $u$, is related to mean basal shear stress, $\bar{\tau}$, by the following equation:

$u=\left(\frac{1}{r}+1\right) C\left(\bar{\tau}+K \rho_{w g h(t)}\right)^{m}$,

where $\rho_{\mathrm{w}}$ is the density of ocean water, $g$ is the gravitational constant, $h(t)$ is the tidal height, $r$ is the ratio between mean sliding velocity and mean forward deformational velocity, $K$ is a site-specific constant varying in proportion to the tidal influence on velocity, $C$ is the sliding coefficient and $m$ is the power law exponent, hereafter taken to be equal to 3. Although sensitive to the value $m$, it has been shown that $m \approx 3$ fits well to data elsewhere (King et al., 2010). Measured GPS velocities and tidal displacements over a 35day period were used to fit parameters for this relationship between basal shear stress and velocity for the Beardmore Glacier. As model parameters are not all independent, separate estimates of shear stress and sliding are made by using

$\tau_{\mathrm{d}}=\rho_{i} g h \sin \alpha$

$u_{\mathrm{s}}=u-\frac{2 A\left(\tau_{\mathrm{b}}\right)^{n}}{n+1} h$,

where $u_{\mathrm{s}}$ is sliding velocity, $\tau_{\mathrm{d}}$ is driving stress, $\tau_{\mathrm{b}}$ is basal shear stress, $h$ is ice thickness and $A$ is the flow rate factor, here taken to be $1.6 \times 10^{-10} \mathrm{a}^{-1} \mathrm{kPa}^{-3}$ for ice at $-20^{\circ} \mathrm{C}$ (Cuffey and Paterson, 2010).

The mean surface slope in the last $10 \mathrm{~km}$ before the grounding line of the Beardmore is 0.017, with an ice thickness of $1050 \mathrm{~m}$ at the centreline measured with groundpenetrating radar at the grounding line during 2010 and backed up by BEDMAP data (Fretwell et al., 2013). This gives an approximate driving stress of $160 \mathrm{kPa}$ (Eq. 2). A very simple approximation of basal shear stress using a "shape factor" of 0.9 gives $\tau_{\mathrm{b}}=144 \mathrm{kPa}$. A simple depthintegrated shallow-ice approximation using the non-linear relation given by Glen's flow law (Nye, 1965) produces a predicted deformation velocity about a quarter of velocities measured on the glacier surface (Eq. 3). This suggests that the contribution of basal sliding to glacier motion is approximately three-quarters of the total observed surface velocity.

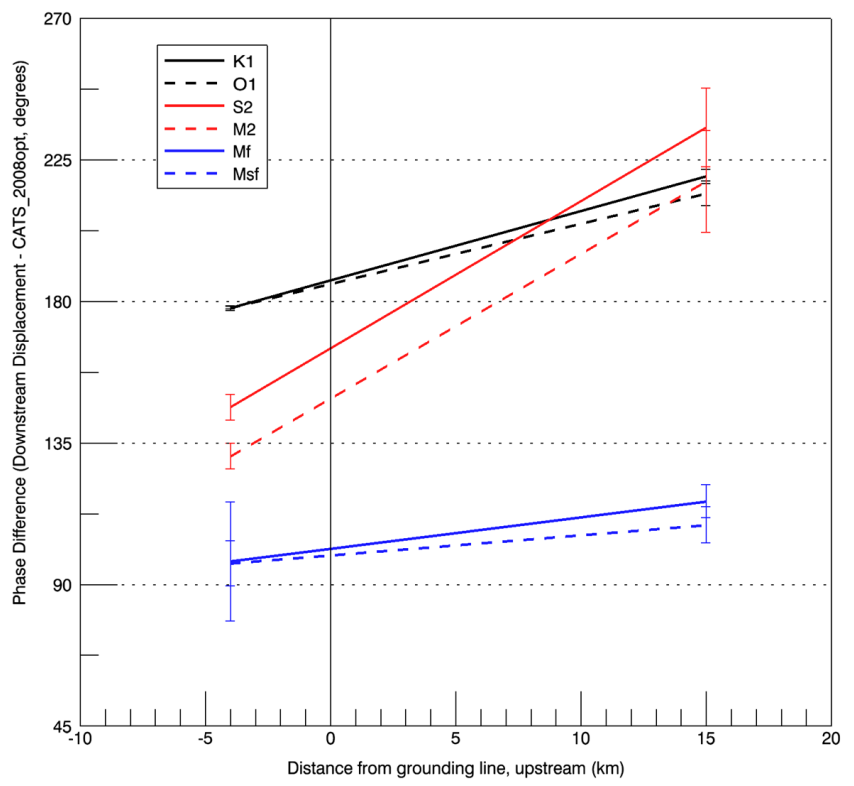

Fig. 5. Phase difference between measured detrended-horizontal displacements in downstream direction at GPS-2 and GPS-3 and modelled vertical ocean tides from the CATS_2008opt tidal simulation (Padman et al., 2008). Phase information for each tidal component is calculated using the t_tide software package (Pawlowicz et al., 2002). Error bars are at $1 \sigma$ confidence intervals.

We use the parameters derived from the fit and tidal information from the CATS2008_opt tidal model to extrapolate the measured velocity dataset to cover a longer time series and predict the expected tidal component of velocity at dates of TerraSAR-X acquisitions (Table 2). With a value of $144 \mathrm{kPa}$ for shear stress, 3 for $r$ and 3 for $m$, the best fit to data is observed with $K=0.8$ and $C=0.246 \times$ $10^{-6} \mathrm{md}^{-1} \mathrm{kPa}^{-3} \cdot r$ and $C$ are mutually dependent (King et al., 2010), and while $r$ is fixed from the calculation of basal sliding, $C$ is calculated through a best fit to observed data.

The dependence of glacier velocity fluctuation on distance upstream of the grounding line is analysed by comparing the phase shift between the observed horizontal displacement from GPS-2 and GPS-3 and vertical ocean tides (Fig. 5). Tidal velocity modulation was too small to be statistically significant at GPS-1 and coverage intermittent at GPS-4. Phase calculations are done using the t_tide software (Pawlowicz et al., 2002). Vertical ocean tides are taken from the CATS_2008opt tidal simulation (Padman et al., 2008) which agrees well with the vertical movement observed in GPS-3 although with a phase shift of around $25 \mathrm{~min}$ in the main diurnal components. The $M_{\mathrm{f}}$ and $M_{\mathrm{sf}}$ tides are estimated separately as the angular resolution is not high enough to solve for both together over such a short measurement period (Gudmundsson, 2007). For the diurnal (K1, O1) and semi-diurnal (S2, M2) components it can be seen that the displacement downstream is generally 180 degrees out of phase with the tides, implying greatest displacement at low 
Table 2. Predicted absolute mean glacier velocity at GPS-3 $(V)$ for TerraSAR-X acquisition periods from tidal response modelling and expected tidal $\left(V_{\mathrm{t}}\right)$ - and atmospheric $\left(V_{\mathrm{IBE}}\right)$-induced error in observed radar look-direction velocity due to vertical displacement.

\begin{tabular}{lccccr}
\hline TSX Pairs & $\Delta$ Tide $(\mathrm{m})$ & $V_{\mathrm{t}}\left(\mathrm{md}^{-1}\right)$ & $\Delta \operatorname{IBE}(\mathrm{m})$ & $V_{\mathrm{IBE}}\left(\mathrm{md}^{-1}\right)$ & $V\left(\mathrm{md}^{-1}\right)$ \\
\hline 1/2 Dec & -0.581 & +0.052 & -0.008 & +0.001 & 1.003 \\
1/2 Mar & -0.469 & +0.042 & +0.083 & -0.008 & 0.973 \\
2/3 Mar & -0.486 & +0.044 & -0.091 & +0.008 & 0.979 \\
1/2 Jun & 0.480 & -0.043 & +0.135 & -0.012 & 0.992 \\
2/3 Jun & 0.0970 & -0.009 & +0.124 & -0.011 & 0.997 \\
\hline
\end{tabular}

tides and maximum velocity during the falling tide. For the fortnightly components $\left(M_{\mathrm{f}}\right.$ and $\left.M_{\mathrm{sf}}\right)$, the peak horizontal displacement downstream is during the falling tide, corresponding to highest velocities during spring tides. The impact of tides on velocities also becomes further delayed upstream. A similar effect with distance upstream has been observed elsewhere, although the delay in all components seems less over a similar distance at the Rutford Ice Stream (Gudmundsson, 2007).

Gudmundsson (2011) showed how long-period velocity fluctuations could occur in response to semi-diurnal tides but were weak in response to diurnal tides when the ice was modelled using viscoelastic rheology. Testing such models requires more detailed knowledge of how glacier velocities vary, both temporally and spatially. The temporal variation in velocity for a single point in the grounding zone is shown in Fig. 2a, while a spatial pattern averaged over time is shown in Fig. 3. Velocity smoothed over 3 days by looking at total horizontal displacement over this period reduces the influence of diurnal tides and highlights a spring-neap fortnightly velocity variation (Fig. 2b). This shows that despite the small variation in this region, velocities from 3-day repeat pass satellite imagery would be sensitive to the acquisition period and not suitable for measuring long-term trends in surface velocity on this glacier. The daily fluctuations are further damped when velocities are calculated over an 11day repeat orbit, such as with TerraSAR-X, and the changes in horizontal velocity predicted by Eq. 1 are largely due to the non-linear interaction between the tidal components over longer periods. As this signal is small for the Beardmore Glacier, it is not clear from the short GPS dataset whether the resulting frequency is at the lunisolar fortnightly period $\left(M_{\mathrm{f}}\right)$ or at the lunisolar synodic fortnightly period $\left(M_{\mathrm{sf}}\right)$ due to the small semi-diurnal tides compared to other regions (Gudmundsson, 2007).

On the Beardmore Glacier the predicted variability in real horizontal velocity due to the diurnal tides over 11 days is $<$ $3 \%$ (Table 2), approximately equivalent to the confidence in the TerraSAR-X velocities of around $0.03 \mathrm{md}^{-1}$. The velocity difference map shown in Fig. 6b shows a velocity increase across the lower glacier from mid-late March 2012 to early April 2012 (a period of only 11 days) where the vertical tide differences are approximately the same. Unlike the vertical signal observed in Fig. 6a, there is no well-defined break at the grounding line and the signal slowly reduces within a few tens of kilometres upstream of the grounding line. Assuming that all observed velocity change is real, the glacier experiences an increase of approximately $0.035 \mathrm{md}^{-1}$, or $4 \%$. This is around 5 to 6 times larger than the $0.006 \mathrm{md}^{-1}$ predicted by the tide response model (Table 2) but falls within the error margin of the TerraSAR-X data.

TerraSAR-X velocities in azimuth direction only from December, March and June are shown along a central flowline for comparison with the predicted velocities from the tide response model (Fig. 6c). By ignoring the range component any bias due to tidal displacement is avoided, and as velocity is largely in azimuth direction results remain representative of trends. There is no discernible change in velocity between these periods well upstream of the grounding line, and although the observed differences approach the predicted absolute error for TerraSAR-X, slightly lower velocities are observed around the grounding line in March and June, agreeing with the tide response model.

\section{Conclusions}

Building on existing knowledge of how glaciers react to tides, it is shown that velocity fluctuations in the grounding zone can be observed using high-resolution satellite data with short repeat pass intervals. On a timescale of 11 days these fluctuations are heavily smoothed and become close to the limit of detection $(<3 \%)$ for the diurnally dominated flow variation on the Beardmore Glacier. The relatively higher basal shear stress in comparison to fast-flowing ice streams is thought to contribute to the limited upstream propagation of these fluctuations (Gudmundsson, 2003) with 1 to $2 \%$ variation in 6-hour averaged velocities during spring tide periods at the GPS $15 \mathrm{~km}$ upstream of the grounding line.

Velocity fluctuations have previously been observed only on ice streams with significant basal sliding. Here we observe $>50 \%$ diurnal fluctuations in GPS records from the grounding zone of the Beardmore Glacier, which are not observed $15 \mathrm{~km}$ upstream from the grounding line. Detrending of daily signals in the grounding zone highlights fortnightly 


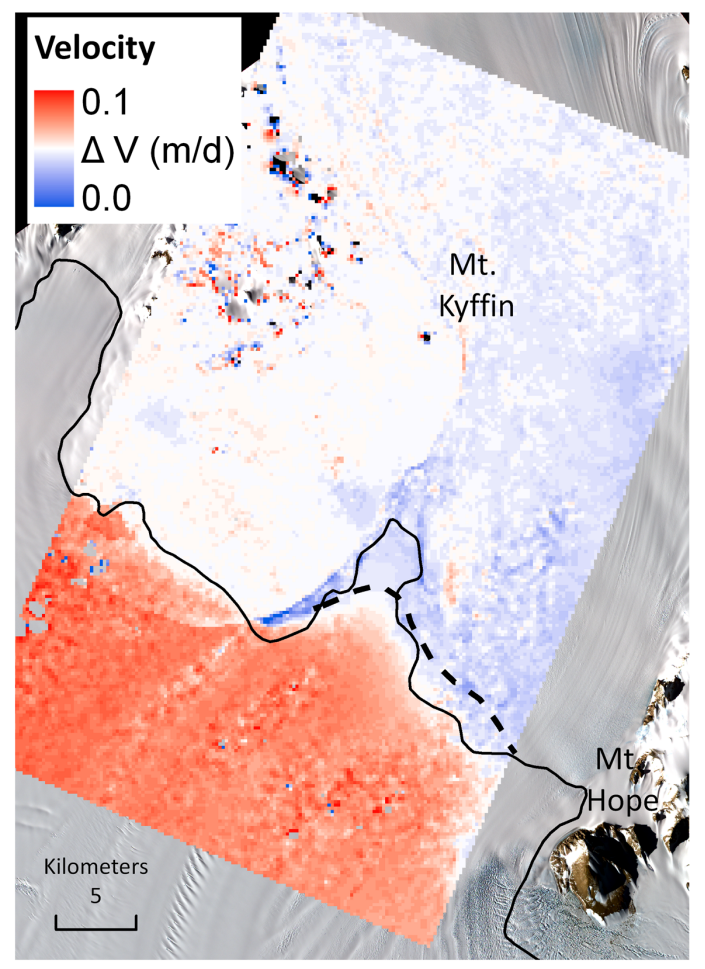

Fig. 6a. Difference in velocity in look direction between $1 / 2$ December and $1 / 2$ June highlighting the influence of the tides downstream of the grounding line.

velocity fluctuation, here with a best fit around $M_{\mathrm{f}}$ period (13.7 days). This is in contrast to observations of the Rutford Ice Stream where interaction of the semi-diurnal tides causes much larger fortnightly fluctuations at the $M_{\text {sf }}$ period. The 5-week data period is not long enough to make a firm statement that this is indeed an $M_{\mathrm{f}}$ signal, which could be a residual effect of the small semi-diurnal tides still present at this site, and longer periods of observation would be necessary to draw further conclusions on the applicability of the Gudmundsson (2007) flow model at this location.

The viability of using SAR speckle tracking to map spatial variability in these short-term velocity fluctuations is also examined. In addition to horizontal displacements, speckle tracking offsets in radar look direction contain a component of the tidal vertical displacement over the ice shelf, proportional to radar incidence angle. This effect distorts calculations of horizontal velocity and flow direction in this area and should be removed using a separate tide model or reference measurements in stagnant areas over the ice shelf nearby. It can also be used to map the grounding zone where tidal range between image acquisitions exceeds the limit of detection for the radar, as is demonstrated for the Beardmore. Fortnightly horizontal velocity changes upstream of the grounding line are too small to be accurately detected here as the non-linear interaction between diurnal tides is thought to be small; however it is quite likely that spatial patterns of velocity fluctua-

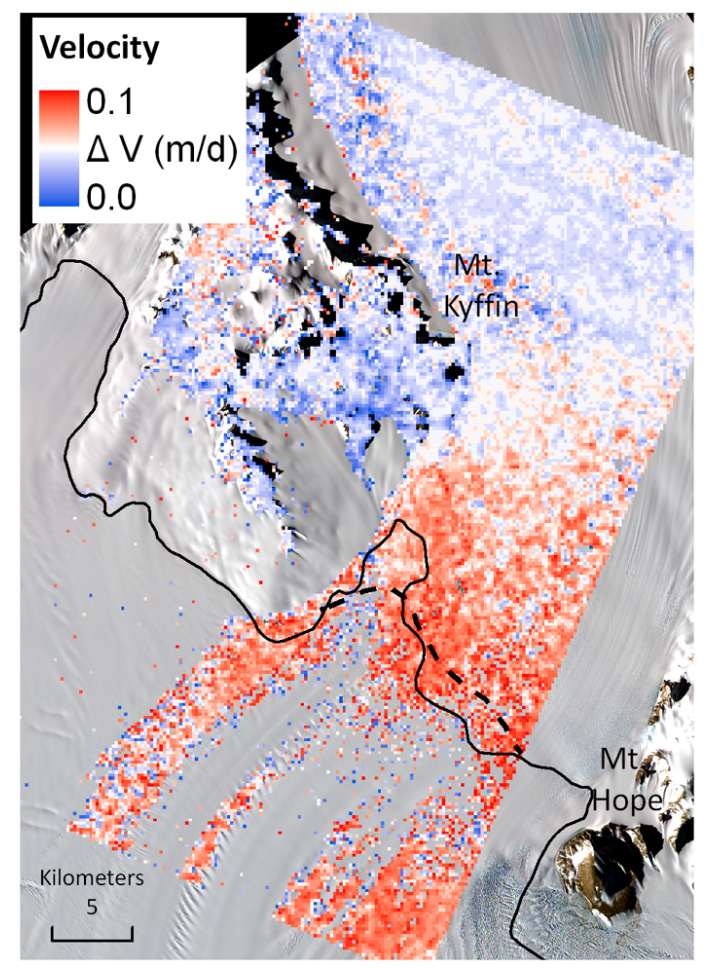

Fig. 6b. Difference in absolute velocity between 1/2 March and 2/3 March. Poor image coherence reduces data quality over the ice shelf.

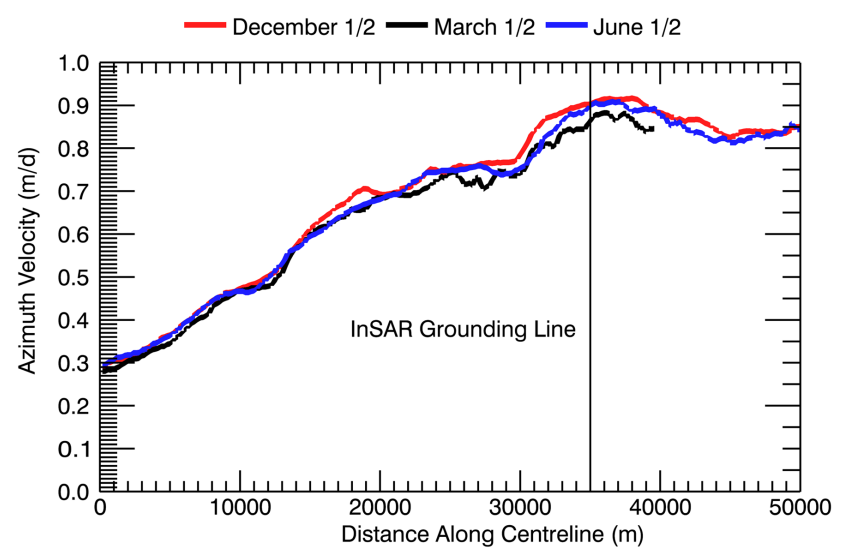

Fig. 6c. TerraSAR-X velocities in radar azimuth direction for December 2010, March 2012 and June 2012. The location of the centreline is shown in Fig. 3 with the origin at the upstream edge of the image.

tion could be detected by this method on ice streams which exhibit stronger fortnightly velocity variations. 
Acknowledgements. TerraSAR-X data were provided by DLR from science proposal HYD1421. ASTER data were provided through the GLIMS project. Fieldwork on the Beardmore Glacier was supported by the US Antarctic Program, Antarctica New Zealand Event K001BI and with assistance from Dean Arthur. Weather station data were provided by the UW-Madison AWS Program. This research was funded, in part, by the Ministry of Business, Innovation and Employment through research contract CO5X1001 to GNS Science. Comments by two anonymous reviewers led to revisions and improvement of the paper.

Edited by: O. Gagliardini

\section{References}

Anandakrishnan, S., Voigt, D. E., Alley, R. B., and King, M. A.: Ice stream $D$ flow speed is strongly modulated by the tide beneath the Ross Ice Shelf, Geophys. Res. Lett., 30, 1361, doi:10.1029/2002GL016329, 2003.

Baessler, M., Rosenau, R., Dietrich, R., Shibuya, K., and Doi, K.: Utilizing InSAR for the measurement of ice flow velocities and ocean tide induced height changes of ice shelves at their grounding zones and surroundings, Proc. IEEE Int. Geoscience and Remote Sensing Symposium (IGARSS), Munich, July 2012, 32493252, 2012.

Bindschadler, R., Choi, H., Wichlacz, A., Bingham, R., Bohlander, J., Brunt, K., Corr, H., Drews, R., Fricker, H., Hall, M., Hindmarsh, R., Kohler, J., Padman, L., Rack, W., Rotschky, G., Urbini, S., Vornberger, P., and Young, N.: Getting around Antarctica: new high-resolution mappings of the grounded and freely-floating boundaries of the Antarctic ice sheet created for the International Polar Year, The Cryosphere, 5, 569-588, doi:10.5194/tc-5-569-2011, 2011.

Bindschadler, R. A., King, M. A., Alley, R. B., Anandakrishnan, S., and Padman, L.: Tidally controlled stick-slip discharge of a West Antarctic ice stream, Science, 301, 1087-1089, 2003.

Breit, H., Fritz, T., Balss, B., Lachaise, M., Niedermeier A., and Vonavka, M.: TerraSAR-X SAR Processing and Products, IEEE TGRS 48, 727-740, 2010.

Brunt, K. M., King, M., Fricker, H. A., and MacAyeal, D. R.: Flow of the Ross Ice Shelf, Antarctica, is modulated by the ocean tide. J. Glaciol., 36, 263-273, 2010.

Burgess, D. O., Sharp, M. J., Mair, D. W. F., Dowdeswell, J. A., and Benham, T. J.: Flow dynamics and iceberg calving rates of Devon Ice Cap, Nunavut, Canada, J. Glaciol., 51, 219-230, doi:10.3189/172756505781829430, 2005.

Cuffey, K. M and Paterson, W. S. B.: The Physics of Glaciers, 4th Edn., Elsevier, 2010.

Doake, C. S. M., Corr, H. F. J., Nicholls, K. W, Gaffikin, A., Jenkins, A., Bertiger, W. I., and King, M. A.: Tide-induced lateral movement of Brunt Ice Shelf, Antarctica, Geophys. Res. Lett., 29, 1226, doi:10.1029/2001GL014606, 2002.

Fretwell, P., Pritchard, H. D., Vaughan, D. G., Bamber, J. L., Barrand, N. E., Bell, R., Bianchi, C., Bingham, R. G., Blankenship, D. D., Casassa, G., Catania, G., Callens, D., Conway, H., Cook, A. J., Corr, H. F. J., Damaske, D., Damm, V., Ferraccioli, F., Forsberg, R., Fujita, S., Gim, Y., Gogineni, P., Griggs, J. A., Hindmarsh, R. C. A., Holmlund, P., Holt, J. W., Jacobel, R. W., Jenkins, A., Jokat, W., Jordan, T., King, E. C., Kohler, J., Krabill,
W., Riger-Kusk, M., Langley, K. A., Leitchenkov, G., Leuschen, C., Luyendyk, B. P., Matsuoka, K., Mouginot, J., Nitsche, F. O., Nogi, Y., Nost, O. A., Popov, S. V., Rignot, E., Rippin, D. M., Rivera, A., Roberts, J., Ross, N., Siegert, M. J., Smith, A. M., Steinhage, D., Studinger, M., Sun, B., Tinto, B. K., Welch, B. C., Wilson, D., Young, D. A., Xiangbin, C., and Zirizzotti, A.: Bedmap2: improved ice bed, surface and thickness datasets for Antarctica, The Cryosphere, 7, 375-393, doi:10.5194/tc-7-3752013, 2013.

Goldstein, R. M., Engelhardt, H., Kamb, B., and Frolich, R. M.: Satellite radar interferometry for monitoring ice-sheet motion application to an Antarctic ice stream, Science, 262, 1525-1530, 1993.

Gudmundsson, G. H.: Transmission of basal variability to a glacier surface, J. Geophys. Res., 108, B52253, doi:10.1029/2002JB002107, 2003.

Gudmundsson, G. H.: Fortnightly variations in the flow velocity of Rutford Ice Stream, West Antarctica, Nature, 444, 1063-1064, 2006.

Gudmundsson, G. H.: Tides and the flow of Rutford Ice Stream, West Antarctica, J. Geophys. Res., 112, F04007, 2007.

Gudmundsson, G. H.: Ice-stream response to ocean tides and the form of the basal sliding law, The Cryosphere, 5, 259-270, doi:10.5194/tc-5-259-2011, 2011.

Holdsworth, G.: Flexure of a floating ice tongue, J. Glaciol., 8, 385397, 1969.

Jezek, K., Abdel Jaber, W., and Floricioiu, D.: TerraSAR-X observations of Antarctic outlet glaciers in the Ross Sea sector, 2011 Proc. IEEE Int. Geo. and Remote Sensing Symposium (IGARSS), 3855-3858, doi:10.1109/IGARSS.2011.6050072, 2011.

Joughin, I.: Ice-sheet velocity mapping: a combined interferometric and speckle-tracking approach, Ann. Glaciol., 34, 195-201, doi:10.3189/172756402781817978, 2002.

Joughin, I., Kwok, R., and Fahnestock, M.: Estimation of ice-sheet motion using satellite radar interferometry: Method and error analysis with application to Humboldt Glacier, Greenland, J. Glaciol., 42, 564-575, 1996.

Joughin, I., Bindschadler, R., King, M. A., Voigt, D., Alley, R. B. Anandakrishnan, S., Horgan, H., Peters, L., Winberry, P., Das, S. B., and Catania, G.: Continued deceleration of Whillans Ice Stream, West Antarctica, Geophys. Res. Lett., 32, L22501, doi:10.1029/2005GL024319, 2005.

Joughin, I., Smith, B. E., and Holland, D. M.: Sensitivity of 21 st century sea level to ocean-induced thinning of Pine Island Glacier, Antarctica, Geophys. Res. Lett., 37, L20502, doi:10.1029/2010GL044819, 2010.

King, M.: Rigorous GPS data-processing strategies for glaciological applications, J. Glaciol., 50, 601-607, doi:10.3189/172756504781829747, 2004.

King, M., Coleman, R., and Morgan, P.: Treatment of horizontal and vertical tidal signals in GPS data: A case study on a floating ice shelf, Earth Planets Space, 52, 1043-1047. 2000.

King, M. A., Murray, T., and Smith, A. M.: Non-linear responses of Rutford Ice Stream, Antarctic, to semi-diurnal and diurnal tidal forcing. J. Glaciol., 56, 167-176, 2010.

Kwok, R. and Fahnestock, M. A.: Ice sheet motion and topography from radar interferometry, IEEE Trans. Geosci. Remote Sens., 34, 189-200, 1996. 
Makinson, K., King, M. A., Nicholls, K. W., and Gudmundsson, G. H.: Diurnal and semidiurnal tide-induced lateral movement of Ronne Ice Shelf, Antarctica, Geophys. Res. Lett., 38, L10501, doi:10.1029/2012GL051636, 2012.

Marsh, O. J. and Rack, W.: A method of calculating ice-shelf surface velocity using ICESat altimetry, Polar Record, 48, 25-30, doi:10.1017/S0032247411000362, 2012.

Nye, J. F.: The flow of a glacier in a channel of rectangular, elliptic of parabolic cross-section, J. Glaciol., 5, 661-690, 1965.

Padman, L., King, M., Goring, D., Corr H., and Coleman, R.: Iceshelf elevation changes due to atmospheric pressure variations, J. Glaciol., 49, 521-526, 2003.

Padman, L., Erofeeva, S. Y., and Fricker, H. A.: Improving Antarctic tide models by assimilation of ICESat laser altimetry over ice shelves, Geophys. Res. Lett., 35, L22504, doi:10.1029/2008GL035592, 2008.

Pawlowicz, R., Beardsley, B., and Lentz, S.: Harmonic analysis including error estimates in MATLAB using T_TIDE, Comput. Geosci., 28, 929-937, 2002.

Rignot, E.: Tidal motion, ice velocity and melt rate of Petermann Gletscher, Greenland, measured from radar interferometry, J. Glaciol., 42, 476-485, 1996.
Rignot, E. and Jacobs, S. S.: Rapid bottom melting widespread near Antarctic ice sheet grounding lines, Science, 296, 2020-2023, doi:10.1126/science.1070942, 2002.

Rignot, E., Bamber, J. L., Van Den Broeke, M. R., Davis, C., Li, Y.H., Van De Berg, W. J., and Van Meijgaard, E.: Recent Antarctic ice mass loss from radar interferometry and regional climate modelling, Nature Geosci., 1, 106-110, 2008.

Rignot, E., Mouginot, J., and Scheuchl, B.: Antarctic grounding line mapping from differential satellite radar interferometry, Geophys. Res. Lett., 38, L10504, doi:10.1029/2011GL047109, 2011.

Scheuchl, B., Mouginot, J., and Rignot, E.: Ice velocity changes in the Ross and Ronne sectors observed using satellite radar data from 1997 and 2009, The Cryosphere, 6, 1019-1030, doi:10.5194/tc-6-1019-2012, 2012.

Swithinbank, C. W.: Ice movement of valley glaciers flowing in the Ross Ice Shelf, Antarctica, Science, 141, 523-524, 1963.

Zumberge, J. F., Heflin, M. B., Jefferson, D. C., Watkins, M. M., and Webb, F. H.: Precise point positioning for the efficient and robust analysis of GPS data from large networks, J. Geophys. Res., 102, 5005-5017, 1997. 